\title{
Exercise and Sinonasal Disease
}

Brecht Steelant, $\mathrm{PhD}^{\mathrm{a}}$, Valerie Hox, MD, PhD ${ }^{\mathrm{b}}$, Peter W. Hellings, MD, PhD ${ }^{\mathrm{a}, \mathrm{c}}$, Dominique M. Bullens, MD, $\mathrm{PhD}^{\mathrm{d}}{ }^{\mathrm{e}}$, Sven F. Seys, $\mathrm{PhD}^{\mathrm{a}, *}$

\section{KEYWORDS}

- Rhinitis • Chronic rhinosinusitis • Nasal hyperreactivity • Nasal obstruction

- Exercise-induced rhinitis • Upper airway disease

\section{KEY POINTS}

- Rhinitis is more common in athletes compared with the general population.

- Timely and proper treatment of upper airway disease in athletes is likely to positively impact their athletic performance.

- More research is needed to elucidate the mechanisms behind upper airway symptoms in athletes.

\section{INTRODUCTION}

Regular physical activity at moderate intensity is beneficial for health and is endorsed by the World Health Organization (WHO). ${ }^{1}$ The nose plays a pivotal role in respiratory physiology, as inhaled air is humidified, heated, and filtered in the nose. ${ }^{2}$ Impaired nasal function due to allergen-, pathogen- or irritant-induced upper airway disease negatively affects exercise performance. ${ }^{3}$ Therefore, the nose and sino-nasal cavities need to function optimally during sport. ${ }^{4,5}$

Rhinitis, defined as symptomatic inflammation of the nasal mucosa causing at least 2 symptoms (congestion, rhinorrhea, nasal pruritis, and/or sneezing), can be caused

Disclosure Statement: The authors declare that they have no competing interests related to this article.

a Laboratory of Clinical Immunology, Department of Microbiology and Immunology, KU Leuven, Herestraat 49, Box 811, Leuven 3000, Belgium; 'b Division of Otorhinolaryngology, Cliniques Universitaires Saint-Luc, Hippocrateslaan 10, 1200 Sint-Lambrechts-Woluwe, Brussels, Belgium; ' Clinical Department of Otorhinolaryngology, Head and Neck Surgery, University Hospitals Leuven, UZ Leuven, Kapucijnevoer 33, Leuven 3000, Belgium; d Paediatric Immunology, Department of Microbiology and Immunology, KU Leuven, Herestraat 49, Box 811,

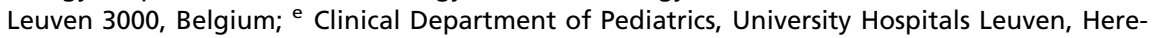
straat 49, Box 811, Leuven 3000, Belgium

* Corresponding author. Laboratory of Clinical Immunology, Department of Microbiology and Immunology, KU Leuven, Herestraat 49, Box 811, Leuven 3000, Belgium.

E-mail address: sven.seys@kuleuven.be 
by infectious organisms, allergic inflammation, or other noninfectious, nonallergic triggers. ${ }^{6}$ It occurs in about $30 \%$ of the Western population and causes notable impacts on quality of life..$^{7,8}$ Rhinosinusitis, inflammation of the nasal mucosa extending to the mucosa of the paranasal sinuses, affects approximately $10 \%$ of the general population. ${ }^{9}$ It is characterized by 2 or more of the following symptoms: nasal blockage, rhinorrhea, facial pain, and/or smell reduction. ${ }^{10}$ Different environmental factors, such as allergens, pathogens and irritants, are known to contribute to the development of sino-nasal disease. ${ }^{11}$ Additional factors, including genetic susceptibility and sensitivity of the airway epithelium, are hypothesized to contribute.

It is possible that there are important mechanistic and clinical links between exercise and sino-nasal function. Although the nasal airway contributes for only $10 \%$ to the overall minute ventilation at maximal exercise, ${ }^{12}$ sino-nasal health may impact the athlete during or outside of exercise. Increased ventilation rates present during exercise increase exposure to allergens, irritants, and pollutants, which subsequently may lead to epithelial cell injury as seen in the development of exerciseinduced bronchoconstriction and asthma. ${ }^{13,14}$ Indeed, regular intensive physical exercise is considered to be a risk factor for developing asthma and/or exerciseinduced bronchoconstriction. ${ }^{15,16}$ A limited number of studies have investigated whether intensive exercise on a regular basis by competitive athletes is associated with a higher prevalence of upper respiratory tract diseases, such as rhinitis and rhinosinusitis. ${ }^{16,17}$

In this review, the authors discuss the epidemiology, mechanism, diagnostic approach, and therapies for sino-nasal disease in the athlete as part of a series of articles designed to give a comprehensive review of the treatment of all airways during exercise.

\section{PREVALENCE OF SINO-NASAL DISEASE IN ATHLETES AND DISEASE SUBTYPES}

Several studies, with variability in diagnostic criteria for rhinitis as well as variability in specific sports studied, have investigated the prevalence of rhinitis in athletes. These estimates range from $8 \%$ to $41 \% .{ }^{18}$ One study, investigating almost 300 German elite athletes, demonstrated significantly higher rates of rhinitis in athletes compared with the general population (25.4\% vs $16.9 \%) .{ }^{19}$ Other large-scale studies in Australian, ${ }^{20}$ Italian, ${ }^{11}$ and Finnish ${ }^{21}$ Olympic athletes provide similar prevalence estimates. A study in US Olympic athletes demonstrated lower rhinitis rates, with only $18 \%$ of athletes affected and no difference compared with controls. ${ }^{22}$

The etiologic subtypes of rhinitis can be divided into infectious, allergic, and nonallergic noninfectious rhinitis.

\section{Infectious Rhinitis in Athletes}

Viral rhinitis or the common cold is a common illness in humans worldwide. It is generally a mild disease; but in athletes, upper respiratory tract infections (URTIs) represent an enormous burden. They occur at an increased frequency when compared with the general population. ${ }^{16,17}$ They are the most common reason for presenting to a sports medicine clinic ${ }^{17,23}$ and are the most common medical problem encountered at both winter and summer Olympics. ${ }^{24,25}$ For example, during the Sydney 2000 Olympic Games, $33 \%$ of all consultations of the New Zealand medical team were categorized as upper respiratory tract illnesses. ${ }^{25}$ Clinical studies show a significant increase in the risk to develop a URTI following extreme endurance events, compared with recreational exercise. ${ }^{26,27}$ Nieman and colleagues ${ }^{26}$ reported that $12.9 \%$ of Los Angeles Marathon runners had a URTI in the week following the marathon versus $2.2 \%$ of 
runners who did not participate. Peters and colleagues ${ }^{27}$ obtained similar results showing a doubling in prevalence of URTI in runners compared with controls, with the highest prevalence in those who achieved the fastest race times.

Most of these data have been based on self-reported symptoms and have often not been validated with objective measures of infection. Moreover, studies looking for pathogens or infectious parameters have failed to identify an infectious cause in as many as $70 \%$ of athletes reporting URTI symptoms. ${ }^{17,28}$ This finding suggests that the noninfectious causes of upper airway symptoms may be underestimated in this population.

\section{Allergic Rhinitis in Athletes}

The most common cause of chronic rhinitis in the general population is allergy with $23 \%$ to $30 \%$ affected in Europe and $12 \%$ to $30 \%$ affected in the United States. ${ }^{29}$ Generally, the prevalence of allergic rhinitis is the highest in the adolescent and young adult population, ${ }^{29}$ the age range comprising most elite athletes.

Pollen allergy may be particularly problematic for the outdoor athlete. Helenius and colleagues $^{30}$ showed in a survey of 49 summer athletes that a clinical presentation of pollen allergy, defined as positive skin prick testing (SPT) in combination with symptoms of seasonal allergic rhinitis, was more common in athletes than in nonathletes. Another study investigating 214 Australian Olympic athletes demonstrated that $41 \%$ of the athletes showed a positive SPT response to any one allergen and $29 \%$ had a clinically proven seasonal allergic rhinoconjunctivitis. ${ }^{31}$ In another series of 265 athletes selected for the Sydney Olympic Games, the prevalence of positive SPT was $32 \%$ and $25 \%$ of athletes had clinical rhinitis. ${ }^{32}$ A questionnaire-based study from Katelaris and colleagues ${ }^{31}$ demonstrated a lower quality of life in pollen-allergic athletes, which improved as the pollen count declined.

\section{Nonallergic/Noninfectious Rhinitis and Exercise-Induced Rhinitis in Athletes}

Many athletes presumably have nonallergic, noninfectious rhinitis (NANIR) or nonallergic rhinitis (NAR) based on population data, ${ }^{33}$ although the specific prevalence data for athletes are not currently available. A recent study investigating field hockey players found lower Allergic Questionnaire for Athletes (AQUA) scores in elite players with rhinitis compared with nonelite players and controls with rhinitis, thus, suggesting (without immunoglobulin E [lgE] detection methods) a nonallergic cause of the upper airway symptoms in the highly trained group. ${ }^{34}$ The causal factors hypothesized to induce NANIR symptoms include chemical irritants (chlorination products, ozone, and other indoor or outdoor pollutants) or physical triggers (changes in temperature, humidity, or osmolality). These triggers are typically known to induce symptoms in patients presenting with nasal hyperreactivity (NHR), ${ }^{35}$ a disease characteristic that can be present in allergic, infectious, and NANIR. ${ }^{36}$

Some specific sports seem to increase the risk for NAR, including winter sports (likely due to continuous exposure to cold dry air) and swimming (likely due to chronic exposure to chlorine and chlorination byproducts). Bonadonna and colleagues ${ }^{37}$ reported a prevalence of almost $50 \%$ of cold-induced rhinitis in 144 skiers. This type of rhinitis mainly presented as rhinorrhea and was present in both atopic as well as nonatopic athletes. A study from 2004 showed a significantly decreased baseline nasal patency and mucociliary clearance time in skiers compared with control values. ${ }^{38}$ Elite swimmers' airways seem to be particularly affected by the chlorination products used to disinfect swimming pools, ${ }^{39}$ and up to $74 \%$ of them complain about rhinitis symptoms. ${ }^{40-42}$ Some studies suggest a higher prevalence of allergic upper 
airway inflammation in this athlete population. ${ }^{42,43}$ However, it is thought that a substantial part of the swimmers with rhinitis have NAR. ${ }^{40}$

\section{Rhinosinusitis in Athletes}

To the authors' knowledge, the prevalence of rhinosinusitis in athletes is largely unknown. The only study reporting on rhinosinusitis prevalence in athletes is the study of swimmers from Gelardi and colleagues, ${ }^{40}$ reporting that $3.2 \%$ of symptomatic swimmers had rhinosinusitis. ${ }^{40}$ Another study describes rhinosinusitis in divers due to barotrauma. ${ }^{44}$ Because infectious and allergic rhinitis are considered to be risk factors for the development of rhinosinusitis, ${ }^{9}$ it is indeed likely that athletes are also more affected compared with their nonathletic peers.

\section{MECHANISMS LEADING TO EXERCISE-INDUCED RHINITIS}

Although few studies investigating the pathophysiology of exercise-induced rhinitis are available, epithelial shedding, neutrophilic pathways, and decreased mucociliary clearance are thought to be involved. Increased sputum neutrophils have been demonstrated in elite swimmers and were associated with the number of training hours. ${ }^{14,45}$ Gelardi and colleagues ${ }^{40}$ found that, in 43 swimmers with rhinitis, $76 \%$ had NAR, of whom $35 \%$ showed a neutrophilic type of nasal inflammation. Interestingly, this neutrophilic inflammation in the nonallergic group disappeared after 1 month when swimmers started using a nasal clip. In another study involving 35 elite swimmers, it was found that in all of them the mucociliary transport time was higher than in normal controls. ${ }^{38}$ Both studies suggest a direct irritant effect on the airway mucosa and mirror earlier studies showing increased numbers of neutrophils in nasal fluid and reduced nasal mucociliary clearance after a marathon. ${ }^{46,47}$ More recently, impaired mucociliary clearance was also shown in healthy athletes after 45-minute runs for 5 days in the polluted streets of Sao Paulo compared with urban forest runs where there was less air pollution. ${ }^{48}$ Whether strenuous exercise contributes to the development of allergic sensitization and inflammation remains debated. Some immunologic studies in athletes have suggested a potential shift of the T-lymphocyte population toward a T-helper 2 subtype on excessive exercise, predisposing them to allergic sensitization. ${ }^{49,50}$

Although some athletes experience improvement in nasal function with exercise (through an increase in nasal sympathetic tone), ${ }^{51}$ it is thought that the increased ventilation during intensive exercise can induce epithelial injury as well as physical and immunologic changes. ${ }^{52}$ In addition, different irritant environments, such as polluted, chlorine-rich, or cold air, might add up or be responsible for these effects as well. Chlorine gas, chloramines (mainly at indoor pools), and hypochlorite may contribute to irritant effects in swimmers. ${ }^{53}$ Increased epithelial shedding and release of damage-associated molecular pattern molecules (uric acid and high mobility group box-1) in sputum was demonstrated in cold-air athletes and elite swimmers, respectively. ${ }^{45}$ These changes might be responsible for the increased nasal symptoms seen in elite athletes. ${ }^{54}$

\section{DIAGNOSIS OF SINO-NASAL DISEASE IN ATHLETES}

Because nasal health is clearly of key importance to the athlete's performance and rhinitis is often underdiagnosed (and undertreated) in this population, early and correct diagnosis of upper airway disease is important.

A thorough history is the cornerstone for making the correct diagnosis. Identification of the symptom-inducing trigger (eg, allergen, infection, cold air, swimming pool, or 
exercise itself) can give clear indications of the type of airway disease one is dealing with and, thus, an outline for an adequate treatment strategy.

Anterior rhinoscopy is the first-line clinical examination to evaluate the nasal mucosa, to check for signs of infection, and to exclude significant structural abnormalities, such as septal deviation. ${ }^{55}$ Nasal endoscopy, on the other hand, offers the advantage of a global evaluation of the nasal cavity and should be considered on suspicion of rhinosinusitis with or without an additional computed tomography scan of the sino-nasal area. ${ }^{9}$

Every athlete presenting with airway symptoms should be screened for allergies as a causal factor of rhinitis. The formal diagnosis of allergic rhinitis is based on a concordance between a typical history of allergic rhinitis symptoms on exposure to the allergen and the detection of allergen-specific IgEs, either by SPT or in the serum by immune assay. ${ }^{29}$ The validated AQUA is often used as a screening tool to identify athletes with allergic disease, and a score of greater than 5 has a positive predictive value of $0.94 .{ }^{56}$

When athletes complain about nasal obstruction, several technical examination methods are available to determine nasal patency, including rhinomanometry, acoustic rhinometry, and peak nasal inspiratory flow measurements. ${ }^{55}$

Finally, in selected cases, it might be useful to test for NHR. Several methods have been evaluated to diagnose this condition, but a nasal cold, dry air challenge has been proven to be the most specific and well tolerated and, therefore, is the method of choice. ${ }^{35}$ When athletes are specifically presenting with exercise-induced rhinitis, testing for NHR is useful as well as an exercise challenge test, including measurements of nasal obstruction and/or evaluation of nasal secretions before and after exercise. At the current time, exercise challenge tests are not validated or standardized as diagnostic tools for exercise-induced rhinitis.

\section{TREATMENT OF SINO-NASAL DISEASE IN ATHLETES}

Elite athletes frequently present with sino-nasal symptoms, which may negatively impact athletic performance and/or recovery. ${ }^{57,58}$ The choice of treatment may depend on the severity of the symptoms and the initiating trigger responsible for the symptoms. Additionally, in order to remain in compliance with World Anti-Doping Agency (WADA) mandates, athletes with sino-nasal problems and treating providers must be cognizant of several medications which require therapeutic use exemptions ${ }^{59}$ (Table 1). It is, therefore, of utmost importance that athletes with upper airway diseases are provided with recommendations tailored to meet their specific needs.

\section{Avoidance of Environmental Triggers}

Intensive exercise in unfavorable environments, such as chlorinated swimming pools, cold air, or areas with high levels of allergens, can lead to an increase in upper respiratory symptoms in specific athletes. Accordingly, avoidance of allergens and/or irritants should be the first step in the treatment of athletes with respiratory diseases. In reality, environmental control is difficult to implement in most cases, especially for athletes participating in sports that occur outdoors in cold weather.

Exposure to irritants, such as chlorine byproducts, should be kept as low as possible. National regulations defining maximum chlorine byproduct levels in swimming pools vary among different countries. The WHO's recent regulations defined a target maximum trichloramine concentration of $0.5 \mathrm{mg} / \mathrm{m}^{3}$ in the air of indoor swimming pools. ${ }^{60}$ Significant ocular and respiratory symptoms have been reported to occur in swimming pool workers and competitive swimmers when airborne 


\begin{tabular}{|c|c|c|c|c|}
\hline Treatment & Disease & Side Effects & $\begin{array}{l}\text { WADA's } \\
\text { Regulations }\end{array}$ & $\begin{array}{l}\text { Annotations/ } \\
\text { Comments }\end{array}$ \\
\hline Antihistamines & $A R$ & $\begin{array}{l}\text { First-generation: } \\
\text { sedation, impair } \\
\text { reaction time } \\
\text { and performance }\end{array}$ & Currently permitted & $\begin{array}{l}\text { Newest molecules: } \\
\text { no sedative effect } \\
\text { and no liver } \\
\text { metabolism }\end{array}$ \\
\hline $\begin{array}{l}\text { Mast cell } \\
\text { stabilizers }\end{array}$ & $A R$ & - & Currently permitted & $\begin{array}{l}\text { Needs to be taken } \\
\text { over few days } \\
\text { before exposure } \\
\text { to obtain } \\
\text { symptom control }\end{array}$ \\
\hline Antileukotrienes & AR & - & Currently permitted & - \\
\hline $\begin{array}{r}\text { Intranasal } \\
\text { steroids }\end{array}$ & $\begin{array}{l}\text { AR, ARS, } \\
\text { CRS }\end{array}$ & $\begin{array}{l}\text { Epistaxis, irritation } \\
\text { of throat and } \\
\text { nose, nasal } \\
\text { dryness }\end{array}$ & Currently permitted & $\begin{array}{l}\text { No systemic effects } \\
\text { compared with } \\
\text { oral/intravenous } \\
\text { steroids }\end{array}$ \\
\hline $\begin{array}{l}\text { Oral/intravenous } \\
\text { steroids }\end{array}$ & $\begin{array}{l}\text { AR, ARS, } \\
\text { CRS }\end{array}$ & Multiple & $\begin{array}{l}\text { Currently requires } \\
\text { therapeutic use } \\
\text { exemption }\end{array}$ & - \\
\hline Decongestants & $\begin{array}{l}\text { AR, ARS, } \\
\text { CRS }\end{array}$ & $\begin{array}{l}\text { Elevated heart } \\
\text { rate and blood } \\
\text { pressure, tremor }\end{array}$ & $\begin{array}{l}\text { Varies based on } \\
\text { medication with } \\
\text { some medications } \\
\text { currently } \\
\text { requiring } \\
\text { therapeutic use } \\
\text { exemption }\end{array}$ & $\begin{array}{l}\text { Rebound effect: } \\
\text { nasal congestion } \\
\text { worsens }\end{array}$ \\
\hline Immunotherapy & AR & $\begin{array}{l}\text { Discomfort at } \\
\text { site of injection; } \\
\text { anaphylaxis }\end{array}$ & Currently permitted & $\begin{array}{l}\text { No exercise in the } \\
\text { hours after } \\
\text { administration }\end{array}$ \\
\hline Antibiotics & ARS, CRS & $\begin{array}{l}\text { Varies based on } \\
\text { medication }\end{array}$ & Currently permitted & $\begin{array}{l}\text { Choice depends on } \\
\text { causative } \\
\text { infectious agents }\end{array}$ \\
\hline
\end{tabular}

Abbreviations: AR, allergic rhinitis; ARS, acute rhinosinusitis; CRS, chronic rhinosinusitis. Data from Refs. ${ }^{73,75,76}$

trichloramine levels exceeded $0.5 \mathrm{mg} / \mathrm{m}^{3}{ }^{61,62}$ Regular monitoring of the airborne trichloramine levels might be considered in addition to the daily water analysis in indoor swimming pools.

When avoidance of environmental triggers does not bring sufficient symptom relief, appropriate pharmacotherapy is recommended to treat upper airway symptoms related to exercise.

\section{Antihistamines and Mast Cell Stabilizers}

Antihistamines are a first-line treatment of athletes with allergic rhinitis to reduce nasal symptoms. ${ }^{63,64}$ Some studies suggest that this class of medication might be effective in patients with NAR and infectious rhinitis. ${ }^{65}$ Older antihistamines are associated with an undesirable sedative effect in some patients, whereas newer antihistamines are less sedating. ${ }^{66}$ Antihistamines can also be administered intranasally, with the advantage of a more rapid onset but with a shorter duration of action. ${ }^{7}$ Antihistamines are currently permitted for use under the WADA's regulations. ${ }^{59}$ 
Cromoglycate is a mast cell stabilizer that can be used intranasally to reduce rhinorrhea, sneezing, and/or itching. Cromolyns are safe but have short half-lives and must be taken for several days to control exercise-related symptoms. The role of mast cells in relation to local epithelial dysfunction and exercise-induced airway disease has previously been demonstrated. ${ }^{67,68}$ Cromolyns are currently permitted for use under the WADA's regulations. ${ }^{59}$

\section{Antileukotrienes}

Leukotriene receptor antagonists (LTRAs) have been shown to reduce nasal symptoms in patients with allergic rhinitis. LTRAs are a nonsedating alternative to common antihistamines. ${ }^{63}$ LTRAs do not have any particular side effects in relation to exercise. ${ }^{69}$ LTRAs are currently permitted for use under the WADA's regulations. ${ }^{59}$

\section{Intranasal Corticosteroids}

Nasal corticosteroids are also a first-line treatment option for allergic rhinitis because of their strong antiinflammatory effect. Nasal corticosteroids have been proven effective and are superior to oral antihistamines in reducing nasal obstruction. ${ }^{70,71}$ In athletes with NAR or chronic rhinosinusitis, intranasal corticosteroids are the therapy of choice. The most common side effects of intranasal corticosteroids are epistaxis, irritation of the throat and nose, and nasal dryness. ${ }^{72}$ Although oral, intravenous, intramuscular, or rectal corticosteroids are prohibited in competition only by the WADA's regulations, nasal corticosteroids are currently permitted. ${ }^{59}$

\section{Decongestants}

Decongestants relieve sino-nasal congestion and are effective in treating symptoms related to infectious as well as mild intermittent allergic rhinitis, if used on a short-term basis. ${ }^{7}$ Common problems associated with decongestants are a mild stimulant effect, tremor, insomnia, and a feeling of increased alertness. Decongestants can also elevate heart rate and blood pressure, a potential problem for athletes with hypertensive issues. Long-term usage of decongestant nasal sprays can result in a rebound effect, leading to an increase in nasal mucosa congestion when the decongestive effect wears off. ${ }^{73}$ Hence, in the absence of any contraindication, the use of decongestants should be limited to about 1 week. The use of many decongestants containing sympathomimetic amines or stimulants is currently prohibited or prohibited in competition only according to the WADA's regulations, and current knowledge of regulations is strongly recommended when prescribing such medications. ${ }^{59}$

\section{Immunotherapy}

Allergen immunotherapy represents a valuable option in athletes with allergic rhinitis, given the potential long-term induction of immune tolerance with regression of symptoms, ${ }^{74}$ the current safety profiles of sublingual and subcutaneous formulations, and the fact that immunotherapy is currently permitted by the WADA's regulations. ${ }^{59}$ It is recommended to start immunotherapy outside the competitive season because it can be accompanied by local or even systemic side effects, mostly during the start-up phase of the treatment. ${ }^{75}$ Strenuous exercise should be avoided in the hours after the injection or intake, as this increases the risk for systemic side effects. ${ }^{74}$

\section{SUMMARY}

Proper sino-nasal function is important for athletes. Sino-nasal disease has been frequently reported in elite athletes and negatively impacts quality of life and sport 
performance. The mechanisms leading to exercise-induced sino-nasal disease in athletes are still poorly understood. In view of the united airway disease concept, sinonasal disease is considered to be a risk factor for the persistence of lower airway symptoms and asthma; therefore, early diagnosis and treatment of sino-nasal symptoms are crucial for athletes in order to control their respiratory function and minimalize the effect on their athletic performance.

\section{ACKNOWLEDGMENTS}

The authors would like to thank Professor Emeritus Jan Ceuppens (KU Leuven, Belgium) for his scientific advice and carefully reviewing the document.

\section{REFERENCES}

1. World_Health_Organization. Global recommendations on physical activity for health. 2010; Available at: http://apps.who.int/iris/bitstream/10665/44399/1/ 9789241599979_eng.pdf. Accessed July 10, 2017.

2. Doulaptsi M, Steelant B, Hellings PW. Treating the nose for controlling the lung: a vanishing story?. In: Bachert C, Bourdin A, Chanez P, editors. The Nose and Sinuses in Respiratory Disorders (ERS Monograph). Sheffield (UK): European Respiratory Society; 2017.

3. Walker A, Surda P, Rossiter M, et al. Nasal function and dysfunction in exercise. J Laryngol Otol 2016;130(5):431-4.

4. Katz RM. Rhinitis in the athlete. J Allergy Clin Immunol 1984;73(5 Pt 2):708-11.

5. Ondolo C, Aversa S, Passali F, et al. Nasal and lung function in competitive swimmers. Acta Otorhinolaryngol Ital 2009;29(3):137-43.

6. Hox V, Maes T, Huvenne W, et al. A chest physician's guide to mechanisms of sinonasal disease. Thorax 2015;70(4):353-8.

7. Bousquet J, Khaltaev N, Cruz AA, et al. Allergic Rhinitis and its Impact on Asthma (ARIA) 2008 update (in collaboration with the World Health Organization, GA(2) LEN and AllerGen). Allergy 2008;63(Suppl 86):8-160.

8. Meltzer EO. Quality of life in adults and children with allergic rhinitis. J Allergy Clin Immunol 2001;108(1 Suppl):S45-53.

9. Fokkens WJ, Lund VJ, Mullol J, et al. EPOS 2012: European position paper on rhinosinusitis and nasal polyps 2012. A summary for otorhinolaryngologists. Rhinology 2012;50(1):1-12.

10. Hastan D, Fokkens WJ, Bachert C, et al. Chronic rhinosinusitis in Europe-an underestimated disease. A GA(2)LEN study. Allergy 2011;66(9):1216-23.

11. Bonini M, Gramiccioni C, Fioretti D, et al. Asthma, allergy and the Olympics: a 12year survey in elite athletes. Curr Opin Allergy Clin Immunol 2015;15(2):184-92.

12. Fregosi RF, Lansing RW. Neural drive to nasal dilator muscles: influence of exercise intensity and oronasal flow partitioning. J Appl Physiol (1985) 1995;79(4): 1330-7.

13. Kippelen P, Fitch KD, Anderson SD, et al. Respiratory health of elite athletes - preventing airway injury: a critical review. Br J Sports Med 2012;46(7):471-6.

14. Seys SF, Hox V, Van Gerven L, et al. Damage-associated molecular pattern and innate cytokine release in the airways of competitive swimmers. Allergy 2015; 70(2): 187-94.

15. Hallstrand TS, Moody MW, Wurfel MM, et al. Inflammatory basis of exerciseinduced bronchoconstriction. Am J Respir Crit Care Med 2005;172(6):679-86.

16. Bonini S, Bonini M, Bousquet J, et al. Rhinitis and asthma in athletes: an ARIA document in collaboration with GA2LEN. Allergy 2006;61(6):681-92. 
17. Spence L, Brown WJ, Pyne DB, et al. Incidence, etiology, and symptomatology of upper respiratory illness in elite athletes. Med Sci Sports Exerc 2007;39(4): 577-86.

18. Schwartz LB, Delgado L, Craig T, et al. Exercise-induced hypersensitivity syndromes in recreational and competitive athletes: a PRACTALL consensus report (what the general practitioner should know about sports and allergy). Allergy 2008;63(8):953-61.

19. Thomas S, Wolfarth B, Wittmer C, et al, study-Team GAL-O. Self-reported asthma and allergies in top athletes compared to the general population - results of the German part of the GA2LEN-Olympic study 2008. Allergy Asthma Clin Immunol 2010;6(1):31.

20. Katelaris $\mathrm{CH}$, Carrozzi FM, Burke TV, et al. Patterns of allergic reactivity and disease in Olympic athletes. Clin J Sport Med 2006;16(5):401-5.

21. Alaranta A, Alaranta $H$, Heliovaara M, et al. Allergic rhinitis and pharmacological management in elite athletes. Med Sci Sports Exerc 2005;37(5):707-11.

22. Weiler JM, Layton T, Hunt M. Asthma in United States Olympic athletes who participated in the 1996 Summer Games. J Allergy Clin Immunol 1998;102(5): 722-6.

23. Nieman DC. Exercise, upper respiratory tract infection, and the immune system. Med Sci Sports Exerc 1994;26(2):128-39.

24. Reeser JC, Willick S, Elstad M. Medical services provided at the Olympic Village polyclinic during the 2002 Salt Lake City Winter Games. WMJ 2003;102(4):20-5.

25. Robinson D, Milne C. Medicine at the 2000 Sydney Olympic Games: the New Zealand health team. Br J Sports Med 2002;36(3):229.

26. Nieman DC, Johanssen LM, Lee JW, et al. Infectious episodes in runners before and after the Los Angeles Marathon. J Sports Med Phys Fitness 1990;30(3): 316-28.

27. Peters EM, Bateman ED. Ultramarathon running and upper respiratory tract infections. An epidemiological survey. S Afr Med J 1983;64(15):582-4.

28. Cox AJ, Gleeson M, Pyne DB, et al. Clinical and laboratory evaluation of upper respiratory symptoms in elite athletes. Clin J Sport Med 2008;18(5):438-45.

29. Brozek JL, Bousquet J, Baena-Cagnani CE, et al. Allergic Rhinitis and its Impact on Asthma (ARIA) guidelines: 2010 revision. J Allergy Clin Immunol 2010;126(3): 466-76.

30. Helenius IJ, Tikkanen HO, Sarna S, et al. Asthma and increased bronchial responsiveness in elite athletes: atopy and sport event as risk factors. J Allergy Clin Immunol 1998;101(5):646-52.

31. Katelaris $\mathrm{CH}$, Carrozzi FM, Burke TV, et al. A springtime Olympics demands special consideration for allergic athletes. J Allergy Clin Immunol 2000;106(2):260-6.

32. Lappuci G, Rasi G, Bonini S, et al. Allergy and infectious diseases in athletes. J Allergy Clin Immunol 2003;11(2 Suppl 1):S142.

33. Hellings PW, Klimek L, Cingi C, et al. Non-allergic rhinitis: position paper of the European Academy of Allergy and Clinical Immunology. Allergy 2017;72(11): 1657-65.

34. Walker A, Surda P, Rossiter M, et al. Rhinitis in elite and non-elite field hockey players. Int J Sports Med 2017;38(1):65-70.

35. Van Gerven L, Boeckxstaens G, Jorissen M, et al. Short-time cold dry air exposure: a useful diagnostic tool for nasal hyperresponsiveness. Laryngoscope 2012;122(12):2615-20.

36. Gerth van Wijk RG, de Graaf-in 't Veld C, Garrelds IM. Nasal hyperreactivity. Rhinology 1999;37(2):50-5. 
37. Bonadonna P, Senna G, Zanon P, et al. Cold-induced rhinitis in skiers-clinical aspects and treatment with ipratropium bromide nasal spray: a randomized controlled trial. Am J Rhinol 2001;15(5):297-301.

38. Passali D, Damiani V, Passali GC, et al. Alterations in rhinosinusal homeostasis in a sportive population: our experience with 106 athletes. Eur Arch Otorhinolaryngol 2004;261(9):502-6.

39. Langdeau JB, Turcotte H, Bowie DM, et al. Airway hyperresponsiveness in elite athletes. Am J Respir Crit Care Med 2000;161(5):1479-84.

40. Gelardi M, Ventura MT, Fiorella R, et al. Allergic and non-allergic rhinitis in swimmers: clinical and cytological aspects. Br J Sports Med 2012;46(1):54-8.

41. Levesque B, Duchesne JF, Gingras S, et al. The determinants of prevalence of health complaints among young competitive swimmers. Int Arch Occup Environ Health 2006;80(1):32-9.

42. Zwick H, Popp W, Budik G, et al. Increased sensitization to aeroallergens in competitive swimmers. Lung 1990;168(2):111-5.

43. Kohlhammer $Y$, Doring $A$, Schafer $T$, et al. Swimming pool attendance and hay fever rates later in life. Allergy 2006;61(11):1305-9.

44. Sonmez G, Uzun G, Mutluoglu M, et al. Paranasal sinus mucosal hypertrophy in experienced divers. Aviat Space Environ Med 2011;82(10):992-4.

45. Bougault V, Turmel J, St-Laurent J, et al. Asthma, airway inflammation and epithelial damage in swimmers and cold-air athletes. Eur Respir J 2009;33(4):740-6.

46. Muns G, Rubinstein I, Singer P. Neutrophil chemotactic activity is increased in nasal secretions of long-distance runners. Int J Sports Med 1996;17(1):56-9.

47. Muns $G$, Singer $P$, Wolf $F$, et al. Impaired nasal mucociliary clearance in long-distance runners. Int J Sports Med 1995;16(4):209-13.

48. Cavalcante de Sa M, Nakagawa NK, Saldiva de Andre CD, et al. Aerobic exercise in polluted urban environments: effects on airway defense mechanisms in young healthy amateur runners. J Breath Res 2016;10(4):046018.

49. Lakier Smith L. Overtraining, excessive exercise, and altered immunity: is this a T helper-1 versus T helper-2 lymphocyte response? Sports Med 2003;33(5): 347-64.

50. Steensberg A, Toft AD, Bruunsgaard H, et al. Strenuous exercise decreases the percentage of type 1 T cells in the circulation. J Appl Physiol (1985) 2001;91(4): 1708-12.

51. Dallimore NS, Eccles R. Changes in human nasal resistance associated with exercise, hyperventilation and rebreathing. Acta Otolaryngol 1977;84(5-6):416-21.

52. Anderson SD, Daviskas E. The mechanism of exercise-induced asthma is. J Allergy Clin Immunol 2000;106(3):453-9.

53. Bernard A. Chlorination products: emerging links with allergic diseases. Curr Med Chem 2007;14(16):1771-82.

54. Stanford CF, Stanford RL. Exercise induced rhinorrhoea (athlete's nose). BMJ 1988;297(6649):660.

55. Hellings PW, Scadding G, Alobid I, et al. Executive summary of European Task Force document on diagnostic tools in rhinology. Rhinology 2012;50(4):339-52.

56. Couto M, Kurowski M, Moreira A, et al. Mechanisms of exercise-induced bronchoconstriction in athletes: current perspectives and future challenges. Allergy 2018;73(1):8-16.

57. Pyne DB, McDonald WA, Gleeson M, et al. Mucosal immunity, respiratory illness, and competitive performance in elite swimmers. Med Sci Sports Exerc 2001; 33(3):348-53. 
58. Pyne DB, Hopkins WG, Batterham AM, et al. Characterising the individual performance responses to mild illness in international swimmers. Br J Sports Med 2005; 39(10):752-6.

59. World_Anti-Doping_Agency. The world anti-doping code international standard. Prohibited list: January, 2017. 2017: Available at: https://www.wada-ama.org/ sites/default/files/resources/files/2016-09-29_-_wada_prohibited_list_2017_eng_ final.pdf. Accessed June 27, 2017.

60. Organization WH. Guidelines for safe recreational water environments. Volume 2: swimming pools and similar environments. 2006. p. xviii. Available at: http://www. who.int/water_sanitation_health/bathing/srwe2full.pdf. Accessed June 27, 2017.

61. Fantuzzi G, Righi E, Predieri G, et al. Airborne trichloramine ( $\mathrm{NCl}(3)$ ) levels and self-reported health symptoms in indoor swimming pool workers: doseresponse relationships. J Expo Sci Environ Epidemiol 2013;23(1):88-93.

62. Seys SF, Feyen L, Keirsbilck S, et al. An outbreak of swimming-pool related respiratory symptoms: an elusive source of trichloramine in a municipal indoor swimming pool. Int J Hyg Environ Health 2015;218(4):386-91.

63. Wei $\mathrm{C}$. The efficacy and safety of $\mathrm{H1}$-antihistamine versus montelukast for allergic rhinitis: a systematic review and meta-analysis. Biomed Pharmacother 2016;83: 989-97.

64. Xu Y, Zhang J, Wang J. The efficacy and safety of selective H1-antihistamine versus leukotriene receptor antagonist for seasonal allergic rhinitis: a meta-analysis. PLoS One 2014;9(11):e112815.

65. De Sutter AI, Saraswat A, van Driel ML. Antihistamines for the common cold. Cochrane Database Syst Rev 2015;(11):CD009345.

66. Passalacqua G, Bousquet J, Bachert C, et al. The clinical safety of H1-receptor antagonists. An EAACI position paper. Allergy 1996;51(10):666-75.

67. Kippelen P, Larsson J, Anderson SD, et al. Effect of sodium cromoglycate on mast cell mediators during hyperpnea in athletes. Med Sci Sports Exerc 2010; 42(10):1853-60.

68. Hallstrand TS, Altemeier WA, Aitken ML, et al. Role of cells and mediators in exercise-induced bronchoconstriction. Immunol Allergy Clin North Am 2013; 33(3):313-28, vii.

69. Steinshamn S, Sandsund M, Sue-Chu M, et al. Effects of montelukast on physical performance and exercise economy in adult asthmatics with exercise-induced bronchoconstriction. Scand J Med Sci Sports 2002;12(4):211-7.

70. Juel-Berg N, Darling P, Bolvig J, et al. Intranasal corticosteroids compared with oral antihistamines in allergic rhinitis: a systematic review and meta-analysis. Am J Rhinol Allergy 2017;31(1):19-28.

71. Okano M. Mechanisms and clinical implications of glucocorticosteroids in the treatment of allergic rhinitis. Clin Exp Immunol 2009;158(2):164-73.

72. Sastre J, Mosges R. Local and systemic safety of intranasal corticosteroids. J Investig Allergol Clin Immunol 2012;22(1):1-12.

73. Greiner AN, Hellings PW, Rotiroti G, et al. Allergic rhinitis. Lancet 2011;378(9809): 2112-22.

74. Keles N. Treating allergic rhinitis in the athlete. Rhinology 2002;40(4):211-4.

75. Katelaris $\mathrm{CH}$, Carrozzi FM, Burke TV. Allergic rhinoconjunctivitis in elite athletes: optimal management for quality of life and performance. Sports Med 2003;33(6): 401-6.

76. Fayock K, Voltz M, Sandella B, et al. Antibiotic precautions in athletes. Sports Health 2014;6(4):321-5. 